\title{
Infectious anxiety disorder
}

A $\mathrm{t}$ the risk of people worrying even more than they already do about their health, we propose adding a new diagnosis to the expanding collection of psychiatric diagnoses: infectious anxiety disorder (IAD). Concerned that a pandemic of anxiety is fast becoming a leading cause of global unhappiness, we propose that better research on IAD, an incredibly contagious form of anxiety, would help combat the worldwide spread of the disorder.

A key element in the early pathogenesis of IAD is concern about shrinking revenues within the "life-sciences" industry. After all, the world contains only a limited number of sick and solvent people, and cures are passé, providing only meager return on investment. The drive for profit is essential to the research-based company's genetic code, and past strategies, which relied heavily on creating "me-toos" and expensive facelifts, are an unsustainable business model.

Faced with this enormous challenge, the life-sciences folks have the potential to develop an ingenious, and some would say foolproof, system: make health anxiety something that transmits well, infects others and spreads easily. By producing treatments not for the sick, but for those anxious about being sick, the life-sciences industry can create whole new markets for "healthypeople products," a term coined by Henry Gadsden, former CEO of Merck.

Producing treatments for the "worried well" makes pharmacy cash registers ring; broadening diagnostic criteria and sprouting "prediseases" have made everyone - and their dogs - candidates for pharmacotherapy. What an incredible business model. In addition to inventing novel molecules to combat diseases, ingenious minds have discovered new diseases to precede them. The best diseases are the chronic ones that can be diagnosed as early as possible (preferably in utero) and require daily, lifelong medication.

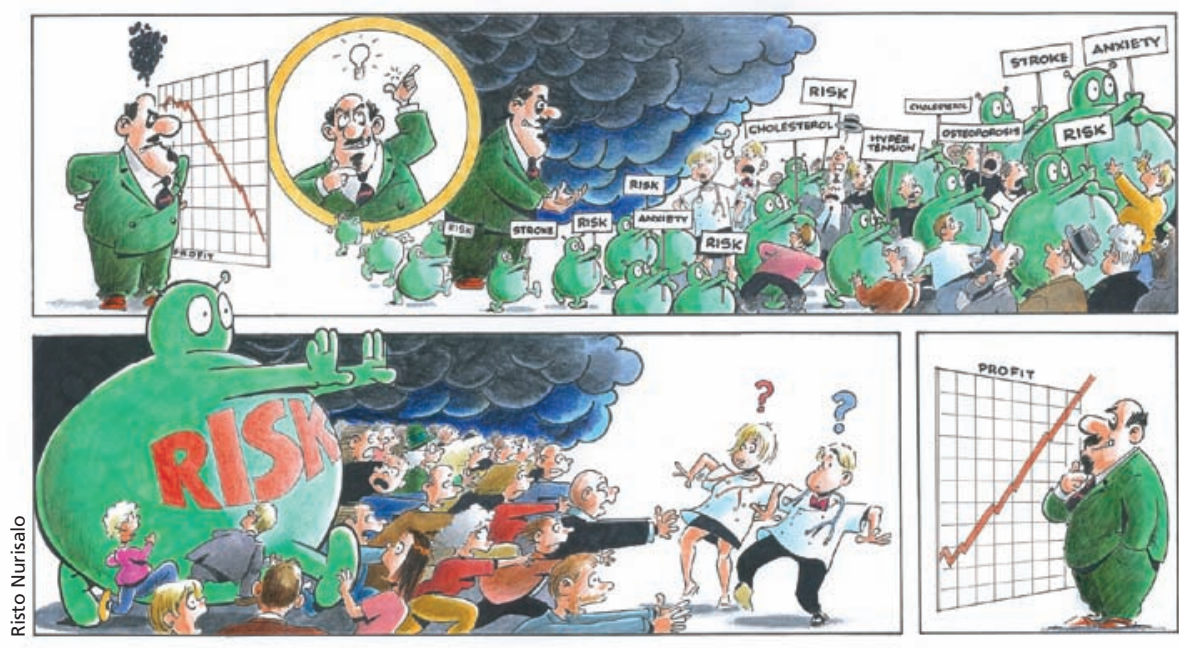

Entanglements between doctors, specialists and patient advocates working with an evidence base that has been designed, published and promoted to meet shareholders' needs have turned ordinary anxiety into an infectious pandemic. Physicians are hammered by clinical guidelines that sing the "underrecognized, underdiagnosed and undertreated" refrain. Is it any wonder docs themselves feel anxious and guilt-ridden? It doesn't help that health-media scare stories fill our waiting rooms with anxious patients stoked by widespread "disease-awareness campaigns" and enough drug advertising to choke a horse.

Part of being a good parent is learning the art of distraction. If you keep kids occupied doing healthy things, then they won't have time to do the unhealthy stuff. The drug industry knows this tactic well. That's why it promotes the physician's central role in diagnosing and treating prediseases. All the extra medical "busyness" leaves physicians with less leisure time to scrutinize the scientific evidence presented to them in prestigious journals.

Let's not forget the lawyers and their role in spreading anxiety throughout medical communities, where even whispers of malpractice suits instill fear in anyone brave enough to veer away from clinical practice guidelines.

The time is ripe to tackle the silly promises of preventive pharmacotherapy and develop some immunity to IAD. For this, there's no pill or vaccine, just good old skepticism. After all, physicians know that despite all the promises that come with preventive pills, most people still get old and sick (and bitter), especially when they learn that the much-publicized relative risk reduction did not apply to them.

Music too might work to banish the spread of IAD. We suggest the song "Don't Worry, Be Happy" as the soundtrack to medicine's drama. After all, being less anxious and more happy is a path many of us can choose, if we want to.

\section{Alan Cassels BA MPA}

Faculty of Human and Social Development University of Victoria

Victoria, BC

Janne Leinonen MD PhD

State Treasury

Helsinki, Finland

Teppo L.N. Järvinen MD PhD

Department of Orthopaedics \& Traumatology Helsinki University Central Hospital Helsinki, Finland

\section{CMAJ 2014. DOI:10.1503/cmaj.140352}

Do you have an opinion about this article? Post your views at www.cmaj.ca. Potential Salon contributors are welcome to send a query to salon@ cmaj.ca. 